\title{
Epidemiology and Risk Factors of Melasma
}

\section{Eleni Tzouveka*}

Sygros Hospital, Athens, Greece

\begin{abstract}
Melasma is one of the most common pigmentary skin disorders. It usually affects women of darker skin types, pregnant women and usually people more exposed to the sun. There are many risk factors associated with melasma, other considered to be predisposing and others considered to be triggering the disorder, when predisposition is present. Still, there are many questions to be answered, in order to better understand its pathophysiology, which will finally lead us to better medication and less relapses of melasma.
\end{abstract}

Keywords: Hyperpigmentation; Melasma; Epidemiology; Risk factors

\section{Introduction}

Melasma is an acquired increased pigmentation of the skin [1], a symmetric hypermelanosis, characterized by irregular light to gray brown macules. Melasma comes from the Greek word melas [= black color), formerly known as Chloasma, another Greek word meaning green color, even though the term was more often used for melasma cases during pregnancy. It is considered to be part of a large group of facial melanosis, such as Riehl's melanosis, Lichen planuspigmentous, erythema dyschromicumperstans, erythrosis and poikiloderma of Civatte [2]. Hyperpigmented macules and patches are most commonly developed in the sun-exposed areas of the skin [3]. Melasma is considered to be a chronic acquired hypermelanosis of the skin [4], with poorly understood pathogenesis [5]. The increased pigmentation and the photo damaged features that characterize melasma include solar elastosis, even though the main pathogenesis still remains unknown [6].

Melasma is considered a common disorder in women of reproductive age with darker skin tones [4], even though appearance in adolescents, older women on certain medication and sometimes men, is not unusual. The increased pigmentation is most commonly located in the cheeks, the upper lip, the chin and the forehead [7].

Melasma may lead to lower self-esteem of the individual, having a significant effect on the patient's emotional well being [8]. The most common facial hyperpigmented macules and patches cause a cosmetic disfigurement with considerable psychological impact [2] and can raise important quality of life issues. Therefore, treatment mainly targets on improving patient clinical outcomes, but it is also very important on its effect on the psychological and emotional aspects of the patients' overall well being [9].

The study of melasma is very complex and today research must include the basic biochemistry, pharmacology and physiology of the melanocortin system, the melanosome development, any genetic diseases associated with pigmentary disorders or even secondary to systemic disease or even environmental exposure to chemicals [10]. In order to better understand the so-far-poorly understood pathogenesis of melasma, scientists should first understand the genomic and proteomic basis of the disease, since hundreds of proteins and other effectors are involved in pigmentation [11].

Since melasma can cause a significant effect on individual emotional well being [8] and its pathogenesis is complex [12], the treatment of the disease is often challenging with frequent relapses.

\section{Epidemiology}

The epidemiology of pigmentary disorders varies in different geographical areas, skin races and age groups. There are numerous studies from different countries of the world, most of which suggesting, if not the same, similar findings and correlations [13].

The most important correlation is between melasma and sex. All studies mentioned in this review prove this, increasing the percentage of women being affected by melasma contrary to men. Studies show that the disease is 7- to 9-times fold more often in women than men.

Another strong link is suggested between melasma and pregnancy [14], since $50-70 \%$ of pregnant women seem to develop melasma [15], whereas women receiving oral contraceptives seem to develop melasma in about $38 \%$ of the cases [16]. Other studies, suggest that the correlation between melasma and pregnancy reach almost $40 \%$ of the cases. On the other hand, data concerning contraceptive pills seem unclear, since some studies suggest that $38 \%$ of women taking contraception will develop melasma, whereas other studies suggest that the number of affected women will not exceed $17 \%[17,18]$.

In countries like Tunisia, where dark skins are more frequent, melasma appears to be the most frequent cause of consultations at dermatology departments [16]. In other countries, like Brazil, data suggest that the age of melasma onset is strongly linked to related skin phototypes [19]. Almost all studies suggest that darker phototypes [Fitzpatrick skin types III-IV) are most prevalent in developing melasma throughout the patient's lifetime, without taking into consideration any of the other known risk factors mentioned above $[9,15,17]$.

Another strong relation is between melasma and the age of onset. Some studies suggest that about $60 \%$ of the patients develop melasma before the age of thirty [16]. Other studies, prove not the age of onset of the disease, but the type of melasma appearing in any stage of the patient's life, for example, extra-facial melasma being more common in menopausal women [19].

Lastly, epidemiological data concerning family history and melasma or melasma and post-inflammatory hyperpigmentation are still very little. Further studies should be carried out, in order for scientists to conclude whether these two last factors are related or not to the development of melasma and in what extent $[15,20]$.

*Corresponding author: Eleni Tzouveka, Sygros Hospital, Athens, Greece, Tel: 210 7265100; E-mail: Elenitzouveka@hotmail.com

Received: October 14, 2014; Accepted: October 22, 2014; Published: October 27,2014

Citation: Tzouveka E (2014) Epidemiology and Risk Factors of Melasma. Pigmentary Disorders S1:002. doi: 10.4172/2376-0427.S1-002

Copyright: (c) 2014 Tzouveka E. The terms of the Creative Commons Attribution License, which permits unrestricted use, distribution, and reproduction in any medium, provided the original author and source are credited. 
Summarizing all the data above, one could tell the strong correlation the disease has with certain factors, such as dark skin, sex, age, whereas concerning other factors conclusion are still very early to be made.

\section{Risk Factors}

The exact cause of melasma is still unknown, even though many factors have been implicated in the disease's pathogenesis [1]. The factors involved as etiologic include genetic influences and predisposition, with $40 \%$ of the patients having at least one relative affected with the disease [4]. Other factors affecting the onset and trigger the onset of melasma include exposure to UV radiation, darker skin colors [16], hormonal changes during pregnancy or hormonal therapies, phototoxic drugs, chemicals and cosmetics and, not rarely, antiseizure therapy or the use of steroids $[2,3,4,21]$. Anxiety traits and psychotropics are lately closely linked to the development of melasma [22], making scientists consider melasma as the mask of stress [23]. All of the above factors are believed to lead to both an increase in melanogenesis and melanocytosis, the basic histological abnormalities seen in melasma [24]. Even though pathogenesis is still unknown, the factors mentioned above are believed to trigger this disorder in people with genetic predisposition. The study of these factors will lead physicians to better management of individual melasma cases, development of preventative measures and even anticipate treatment results and recurrence [15].

The onset of melasma is proven by impaired stratum corneum integrity and delayed barrier recovery rate [6], whereas an increased number of inflammatory cells in the lesion are usual findings during the development of melasma in Asian skin [25].

The role of hormonal levels, either during the pregnancy period or due to hormonal therapy, is considered to be, if not the most important factor, one of the most factors influencing the onset and development of melasma [7,26]. During pregnancy, immunologic, endocrine, metabolic and vascular changes make pregnant women susceptible to changes of the skin and its appendages [27]. Estrogen, progesterone and Melanocyte-Stimulating Hormone (MSH), which are normally increased during pregnancy and even more during the third trimester, are believed to trigger the onset of melasma, even though numerous cases have been found to have no increased levels of the above hormones. However, some scientists suggest that hormonal alterations with low estrogen levels and high LH levels, due to ovarian dysfunction, may underlie the pathogenesis of some cases of idiopathic melasma [28].

Besides pregnancy, women given contraceptive pills containing progesterone or post-menopausal women given progesterone for hormonal therapy, to which extra-facial melasma was more common [19], develop melasma, making progesterone one of the most important factors for the disease [29]. Remarkably, the hyperpigmentation due to combined or sequential contraceptive pills does not completely regress after cessation, in contrast to melanoderma in pregnant women $[13,30]$. Scientists, however, have pointed that estrogen receptor and progesterone receptor expression in melasma-affected skin needs to be further investigated and clarified, studies that may lead to the development of topical anti-estrogen therapies for melasma [31].

UV light is another very important factor, whose role has been appointed and proven by numerous studies and case reports $[3,22,24,32]$. UV-B, UV-A as well as visible light are all capable of stimulating melanogenesis. The above are not considered to be able to cause melasma without genetic predisposition or hormonal changes, but are thought to be very important in triggering the disease, if the background exists.
Apart from genetic predisposition, systemic disorders and autoimmunity are strongly linked to the appearance and development of the disease. Systemic disorders, such as Addison's disease, should always be suspected and excluded in clinically relevant cases [32]. Thyroid autoimmunity is also considered to be an important factor for the onset of melasma, since a considerable number of women with Hashimoto's disease develop melasma and women during their pregnancy who develop melasma, will or already have developed thyroid autoimmunity [33].

Lastly, other factors have been implicated having an important role in the development of melasma, such as lentigines and melanocytic nevi. Even though, the existence of the above is not so strongly linked to the onset and development of melasma, as the other factors mentioned, further studies are needed to show whether there is a correlation between lentigines and melanocytic nevi and melasma [34].

Even though, melasma is more often seen in women, a few studies have been carried out in men having melasma. The most important factors pointed in these studies for the development of melasma are considered to be sunlight exposure, use of cosmetics, infections and hepatic disorders and familial hyperpigmentation [35,36]. Even though few in numbers, some studies suggest that circulating $\mathrm{LH}$ was significantly higher in melasmic men, whereas testosterone was markedly low in the same group, data that suggest that melasma may involve subtle testicular resistance [37].

All of the above risk factors have been suggested to trigger the onset and development of melasma, even though there is still a lot to be studied. These studies may provide information about the management of melasma cases, support preventative measures and anticipate treatment results and recurrence [15]. Identifying other associated to melasma factors should provide new targets for a more efficient treatment of melasma and a better prevention of the relapses [12].

\section{References}

1. Achar A, Rathi SK (2011) Melasma: a clinico-epidemiological study of 312 cases. Indian J Dermatol 56: 380-382.

2. Khanna N, Rasool S (2011) Facial melanoses: Indian perspective. Indian J Dermatol Venereol Leprol 77: 552-563.

3. Grimes PE (1995) Melasma. Etiologic and therapeutic considerations. Arch Dermatol 131: 1453-1457.

4. Handel AC, Miot LD, Miot HA (2014) Melasma: a clinical and epidemiologica review. An Bras Dermatol 89: 771-782.

5. Kang HY, Suzuki I, Lee DJ, Ha J, Reiniche P, et al. (2011) Transcriptional profiling shows altered expression of wnt pathway- and lipid metabolismrelated genes as well as melanogenesis-related genes in melasma. J Invest Dermatol 131:1692-1700.

6. Lee DJ, Lee J, Ha J, Park KC, Ortonne JP, et al. (2012) Defective barrier function in melasma skin. J Eur Acad Dermatol Venereol 26: 1533-1537.

7. Bolanca I, Bolanca Z, Kuna K, VukoviÄ $\ddagger$ A, Tuckar N, et al. (2008) Chloasma-the mask of pregnancy. Coll Antropol 32 Suppl 2: 139-141.

8. Freitag FM, Cestari TF, Leopoldo LR, Paludo P, Boza JC (2008) Effect of melasma on quality of life in a sample of women living in southern Brazil. J Eur Acad Dermatol Venereol 22: 655-662.

9. Perez M, Luke J, Rossi A (2011) Melasma in Latin Americans. J Drugs Dermatol 10: $517-523$

10. Grimes P, Nordlund JJ, Pandya AG, Taylor S, Rendon M, et al. (2006) Increasing our understanding of pigmentary disorders. J Am Acad Dermatol 54: S255-261.

11. Ortonne JP, Bissett DL (2008) Latest insights into skin hyperpigmentation. J Investig Dermatol Symp Proc 13: 10-14.

12. Passeron $T$ (2013) Melasma pathogenesis and influencing factors - an overview of the latest research. J Eur Acad Dermatol Venereol 27 Suppl 1: 5-6. 
13. Elling SV, Powell FC (1997) Physiological changes in the skin during pregnancy. Clin Dermatol 15: 35-43.

14. Dogra S, Sarangal R (2014) Pigmentary disorders: An insight. Pigment International 1: 5-7

15. Ortonne JP, Arellano I, Berneburg M, Cestari T, Chan H, et al. (2009) A global survey of the role of ultraviolet radiation and hormonal influences in the development of melasma. J Eur Acad Dermatol Venereol 23: 1254-1262.

16. Guinot C, Cheffai S, Latreille J, Dhaoui MA, Youssef S, et al. (2010) Aggravating factors for melasma: a prospective study in 197 Tunisian patients. J Eur Acad Dermatol Venereol 24: 1060-1069.

17. Victor FC, Gelber J, Rao B (2004) Melasma: a review. J Cutan Med Surg 8: 97-102.

18. Tamega Ade A, Miot LD, Bonfietti C, Gige TC, Marques ME, et al. (2013) Clinical patterns and epidemiological characteristics of facial melasma in Brazilian women. J Eur Acad Dermatol Venereol 27: 151-156.

19. Hexsel D, Lacerda DA, Cavalcante AS, Machado Filho CA, Kalil CL, et al. (2014) Epidemiology of melasma in Brazilian patients: a multicenter study. Int J Dermatol 53: 440-444.

20. Adalatkhah H, Sadeghi Bazargani H2 (2013) The association between melasma and postinï 7 ,ammatory hyperpigmentation in acne patients. Iran Red Crescent Med J 15: 400-403.

21. Wu IB, Lambert C, Lotti TM, Hercogová J, Sintim-Damoa A, et al. (2012) Melasma. G Ital Dermatol Venereol 147: 413-418.

22. Handel AC, Lima PB, Tonolli VM, Miot LD, Miot HA (2014) Risk factors for facia melasma in women: a case-control study. Br J Dermatol 171: 588-594.

23. Wolf R, Wolf D, Tamir A, Politi $Y$ (1991) Melasma: a mask of stress. Br J Dermatol 125: 192-193.

24. Jadotte YT, Schwartz RA (2010) Melasma: insights and perspectives. Acta Dermatovenerol Croat 18: 124-129.

25. Noh TK, Choi SJ, Chung BY, Kang JS, Lee JH, et al. (2014) Inflammatory features of melasma lesions in Asian skin. J Dermatol 41: 788-794.
26. Moin A, Jabery Z, Fallah N (2006) Prevalence and awareness of melasma during pregnancy. Int J Dermatol 45: 285-288.

27. Rathore SP, Gupta S, Gupta V (2011) Pattern and prevalence of physiologica cutaneous changes in pregnancy: a study of 2000 antenatal women. Indian J Dermatol Venereol Leprol 77: 402.

28. Pérez M, Sánchez JL, Aguiló F (1983) Endocrinologic profile of patients with idiopathic melasma. J Invest Dermatol 81: 543-545.

29. Jang YH, Lee JY, Kang HY, Lee ES, Kim YC (2010) Oestrogen and progesterone receptor expression in melasma: an immunohistochemical analysis. J Eur Acad Dermatol Venereol 24: 1312-1316.

30. Resnik S (1967) Melasma induced by oral contraceptive drugs. JAMA 199: 601-605.

31. Lieberman R, Moy L (2008) Estrogen receptor expression in melasma: results from facial skin of affected patients. J Drugs Dermatol 7: 463-465.

32. Nicolaidou E, Antoniou C, Katsambas AD (2007) Origin, clinical presentation, and diagnosis of facial hypermelanoses. Dermatol Clin 25: 321-326, viii.

33. Lutfi RJ, Fridmanis M, Misiunas AL, Pafume O, Gonzalez EA, et al. (1985) Association of melasma with thyroid autoimmunity and other thyroidal abnormalities and their relationship to the origin of the melasma. $\mathrm{J}$ Clin Endocrinol Metab 61: 28-31.

34. Adalatkhah H, Sadeghi-bazargani H, Amini-sani N, Zeynizadeh S (2008) Melasma and its association with different types of nevi in women: a casecontrol study. BMC Dermatol 8: 3

35. Sarkar R, Puri P, Jain RK, Singh A, Desai A (2010) Melasma in men: a clinical, aetiological and histological study. J Eur Acad Dermatol Venereol 24: 768-772.

36. Vachiramon V, Suchonwanit $P$, Thadanipon $K$ (2012) Melasma in men. J Cosmet Dermatol 11: 151-157.

37. Sialy R, Hassan I, Kaur I, Dash RJ (2000) Melasma in men: a hormonal profile J Dermatol 27: 64-65.
This article was originally published in a special issue, Melasma handled by Editor(s). Dr. Serena Gianfaldoni, University of Pisa, Italy 